\title{
Low-dose L-methionine-associated Changes in Behavioural Indices in Young Rats
}

\author{
Adejoke Y. Onaolapo ${ }^{1}$, Olakunle J. Onaolapo ${ }^{2, *}$, Ibekwe C. Blessing ${ }^{1}$, Sulaiman A. Hameed ${ }^{1}$, Rauf Raimot ${ }^{1}$ \\ ${ }^{1}$ Department of Anatomy, Faculty of Basic Medical Sciences, College of Health Sciences, Ladoke Akintola University of Technology, \\ Nigeria \\ ${ }^{2}$ Department of Pharmacology and Therapeutics, Faculty of Basic Medical Sciences, College of Health Sciences, Ladoke Akintola \\ University of Technology, Nigeria
}

Copyright $(2016$ by authors, all rights reserved. Authors agree that this article remains permanently open access under the terms of the Creative Commons Attribution License 4.0 International License

\begin{abstract}
Objective: The study objectives were to investigate the effects of L-methionine (at low doses) on open-field novelty-induced behaviours, anxiety-related behaviours, working-memory and brain S-adenosyl-methionine (SAMe) levels in young rats. This was with a view to determine whether administration of low doses of L-methionine can significantly alter behavioural parameters, working-memory and brain SAMe levels, or not. Methodology: Wistar rats (40-45 g each) were given distilled water or L-methionine ( 5 and $10 \mathrm{mg} / \mathrm{kg}$ body weight) orally for 21 days. Behaviours were assessed after the first and last dose of L-methionine. Results: In the open field, significant increases in horizontal locomotion and rearing were seen after the first dose, while repeated administration led to their suppression. Suppression of grooming behaviour was observed at both times of assessment. Working-memory in the radial-arm maze was significantly reduced following repeated administration; while the elevated plus-maze test revealed anxiolytic responses following both acute and repeated administration. Patterns of changes in horizontal locomotion in the y-maze and radial-arm maze were similar to that of the open-field. There was no significant difference in brain levels of SAMe at end of study. Conclusion: The study demonstrated an association between low dose L-methionine administration and behavioural changes in young rats. It therefore brings to light, the behavioural changes that may occur due to addition of low doses of L-methionine to the diet.
\end{abstract}

Keywords Amino Acid, Brain, Behaviour, Memory, Spontaneous-behaviour, Anxiety

\section{Introduction}

Methionine, a proteinogenic, essential, a-amino acid is found in high concentrations in fish, meat, and dairy products $[1,2]$. It is one of the principal sulphur-containing amino acids that play critical roles in cellular metabolism, immune-cell production, proper nerve functioning [1], growth and development [2]. Methionine is also the precursor for a number of biochemical molecules, and its breakdown generates metabolites that are important in a number of cellular functions [3]. Methionine metabolism occurs primarily via transmethylation pathway; as its conversion to S-adenosyl methionine (SAMe) (a very important methyl donor), through the activity of the enzyme methionine adenosyltransferase [4], occurs through this pathway, which also generates S-adenosyl homocysteine (SAH), and homocysteine. Complete metabolism of methionine is critical to a large number of biochemical processes in the body [5,6]; however, dietary deficiencies, genetic polymorphisms, and enzymatic blocks or inactivity can negatively impact normal methionine metabolism [4]. SAMe, a metabolite of methionine is an antidepressant [7], but its use is constrained by its cost and the relative instability of its formulations [8]. Studies have shown that administration of methionine increases brain levels of SAMe in rats [7,9]. Oral administration of L-methionine had even been reported to be better than direct administration of SAMe for increasing brain levels of SAMe [7]; suggesting that it could be used as an antidepressant.

Methionine is transported into the brain via the large neutral amino acids transporter [10], which is active in all regions of the brain. Previous studies assessing the effects of methionine have used doses $\geq 100 \mathrm{mg} / \mathrm{kg}$ [11], usually administered in drinking water or in diet. These studies have also reported mixed neurobehavioural responses [1,12-16]. Methionine has been reported to cause locomotor retardation, memory impairment and anxiety [14,17], but in a few studies, no behavioural effects were seen $[15,16]$. Methionine metabolites like homocysteine have also been linked to reduction in learning and long-term potentiation $[7,18,19]$, while SAMe has been associated with memory improvement [20]. 
Acute or repeated administration of high doses of methionine is associated with hypermethioninaemia, which has serious health implications [21,22]. Therefore, if L-methionine is to be used for its possible antidepressant properties, preliminary studies are required to ascertain that its usage, at doses below the recommended dietary allowance in humans aged from two years and above (13-27 $\mathrm{mg} / \mathrm{kg}$ ) [23], has any significant effect on behaviour. However, there is a dearth of information on the behavioural effects of methionine supplementation at these doses. The rationale for this study was the need to ascertain the effects of oral methionine at 5 and $10 \mathrm{mg} / \mathrm{kg}$ on selected neurobehavioural tests and brain SAMe levels in young rats, and to compare the effects on memory and anxiety-related behaviours against standard reference drugs. We tested the hypothesis, that acute or repeated administration of L-methionine could significantly alter brain SAMe levels, novelty-induced behaviours in the open field, spatial working-memory and anxiety-related behaviours.

\section{Materials and Methods}

\subsection{Equipment and Apparatus}

Open-field for novelty-induced behaviours, Y-maze and Radial-arm maze for working-memory tests, and Elevated plus-maze for anxiety test.

\subsection{Dietary Supplements}

L-methionine tablets that were crushed and dissolved in distilled water.

\subsection{Animals}

Eight-week old Wistar rats from Empire Breeders, Osogbo, Osun State, Nigeria, weighing 40-45 g each were used for the study. Rats were housed in groups of six in plastic cages located in a temperature-controlled quarters (22-25 degree Celsius) with 12 hours of light daily. All groups of animals were fed using commercial standard chow (Calories: $29 \%$ protein, $13 \%$ fat, $58 \%$ carbohydrate, Nutrients: $0.59 \%$ Methionine and $0.39 \%$ Cystine among others) from weaning. Rats had free access to food and tap water ad libitum, except during the behavioural tests. All procedures were conducted in accordance with the approved institutional protocols and within the provisions for animal care and use prescribed in the scientific procedures on living animals, European Council Directive (EU2010/63).

\subsection{Experimental Method}

One hundred and thirty-two healthy female rats were randomly assigned into three main groups based on the behavioural tests carried out on them (Table 1): Open field (36), working-memory (48) and anxiety test (48). They were further divided into 3 groups of 12 animals each, for the open field test and 4 groups of 12 animals each, for the memory and anxiety tests respectively. Diazepam (DIZ) and Scopolamine (SCOP) were used as standard reference drugs for anxiety and memory tests. Rats were administered distilled water at $10 \mathrm{ml} / \mathrm{kg}$, a standard drug (diazepam at 0.5 $\mathrm{mg} / \mathrm{kg}$ for the anxiety test and scopolamine at $1 \mathrm{mg} / \mathrm{kg}$ for cognition test) or one of two doses of L-methionine (5 and 10 $\mathrm{mg} / \mathrm{kg}$ ) daily for 21 days, via an oral cannula. All animals were gavaged daily, starting at 9.00 a.m. Route of administration of drug or vehicle was oral; to simulate the method of administration of SAMe if it were to be used as an antidepressant. Doses of L-methionine were calculated by crushing the tablets and dissolving measured quantities in distilled water. Rats (Open field group) were weighed weekly. Behavioural tests were carried out 30 minutes after the first and last dose of vehicle or L-methionine. At the end of the experimental period, animals were anaesthetized with diethyl-ether, following which they were decapitated. Brains were removed and homogenized to assess SAMe levels.

Table 1. Experimental groups and number of animals in each test group (n).

\begin{tabular}{cccc}
\hline Groups & & Test & \\
& Open-Field & Working-memory & Anxiety \\
DW $(10 \mathrm{ml} / \mathrm{kg})$ & $\mathrm{n}=12$ & $\mathrm{n}=12$ & $\mathrm{n}=12$ \\
MET5 $(5 \mathrm{mg} / \mathrm{kg})$ & $\mathrm{n}=12$ & $\mathrm{n}=12$ & $\mathrm{n}=12$ \\
MET10 $(10 \mathrm{mg} / \mathrm{kg})$ & $\mathrm{n}=12$ & $\mathrm{n}=12$ & $\mathrm{n}=12$ \\
SCOP $(1 \mathrm{mg} / \mathrm{kg})$ & & $\mathrm{n}=12$ & \\
DIZ $(0.5 \mathrm{mg} / \mathrm{kg})$ & & & $\mathrm{n}=12$ \\
TOTAL & 36 & 48 & 48 \\
\hline
\end{tabular}

\subsubsection{Behavioural testing}

Behavioural tests were carried out in a quiet room between the hours of 9 a.m. and 2 p.m. On each of the test days, rats were transported in their home cages to the testing room, and allowed 30 minutes to acclimatize before testing. At the beginning of the behavioural tests, each animal was placed in the apparatus and its behaviour videotaped for subsequent analysis. After testing, each rat was removed from the maze and returned to its home cage, and all interior surfaces were cleaned thoroughly with $70 \%$ ethanol and then wiped dry to remove any trace of odour.

\subsubsection{Open Field:}

Horizontal locomotion, rearing and grooming were recorded in the open field over a twenty minute period [24]. The open field box is a rectangular arena composed of a hard floor measuring $36 \times 36 \times 26 \mathrm{~cm}$, with its floor divided by permanent red markings into 16 equal squares. The rats were placed in the centre of the field and covered by a small dome that was then removed at the beginning of video recording of their activities. After administration of vehicle or L-methionine, each rat was introduced into the field and the total horizontal locomotion (number of floor units entered with all paws), rearing frequency (number of times the 
animal stood on its hind legs either with its fore arms against the walls of the observation cage or free in the air) and frequency of grooming (number of body cleaning with paws, picking of the body and pubis with the mouth and face washing actions, indicative of a stereotypic behaviour) within the 20 minute interval was recorded.

\subsubsection{Memory (Y-maze, Radial-arm maze)}

Y-maze and the radial-arm maze were used to measure spontaneous alternation working-memory and locomotor activity. Spontaneous alternation in the Y-maze was assessed using a maze composed of three equally spaced arms $\left(120^{\circ}\right.$, $41 \mathrm{~cm}$ long and $15 \mathrm{~cm}$ high, $5 \mathrm{~cm}$ wide). Each rat was placed in one of the arm compartments and allowed to move freely until its tail completely entered another arm. The sequence of arm entries was recorded. An alternation was defined as entry into all three arms consecutively. The number of actual alternations is number of sequential arm entries into three arms, designated $\mathrm{A}, \mathrm{B}$ and $\mathrm{C}$. The percentage alternation is calculated as $\{$ (Actual alternations/Total arm entry minus two) $x 100\}$ in a 5 minute interval [25].

Working-memory in the radial-arm maze was measured as alternation index, which is the ratio of sequential arm entries before error and total arm entry. The apparatus consists of eight equidistantly spaced arms, each about $33 \mathrm{~cm}$ long, all radiating from a small circular central platform. Working memory was assessed when the rat enters each arm a single time. Re-entry into the arms would result in a workingmemory error [25].

\subsubsection{Anxiety Model: Elevated plus-maze (EPM)}

The EPM validated for use in rats, relies upon rodents' proclivity toward dark, enclosed spaces (approach) and an unconditioned fear of heights/open spaces (avoidance). It is plus-shaped, with two open arms measuring $25 \times 5 \times 5 \mathrm{~cm}$ lying across from each other and perpendicular to two closed arms measuring $25 \times 5 \times 16 \mathrm{~cm}$ with a centre platform $(5 \times 5$ $\mathrm{x} 0.5 \mathrm{~cm})$. The closed arms are enclosed by 2 high walls $(16$ $\mathrm{cm})$ while the open arms have no side wall. Animals are placed in the central platform facing the closed arm and behaviours recorded for 5 minutes. The criterion for arm visit is considered only when the animal decisively moved all its four limbs into an arm [26].

\subsection{S-adenosyl Methionine Assay}

Brain was homogenized $(1: 10, \quad w / v)$ in ice-cold phosphate-buffered saline using Teflon-glass homogenizer. Homogenate was centrifuged at $10,000 \mathrm{rpm}$ at $4{ }^{\circ} \mathrm{C}$ for 15 minutes to remove cell debris. Total brain SAMe level was measured using commercially-available ELISA kits. Brain supernatant was added to conjugate coated plates and incubated on an orbital shaker at 25 degree Celsius for 10 minutes following the manufacturer's instruction. The kits had a detection sensitivity of $185 \mathrm{ng} / \mathrm{ml}$. Colour change was measured at an optical density of $450 \mathrm{~nm}$, and the concentration of SAMe in sample determined.

\subsection{Statistical Analysis}

Data was analysed using Chris Rorden's ezANOVA for windows. Hypothesis was tested using analysis of variance (ANOVA). We tested the hypothesis that acute or repeated oral administration of low doses of L-methionine could significantly alter behaviours in young rats. Two-factor ANOVA was used to test effects of dose of L-methionine and duration of administration (acute versus repeated) on behaviour while one way ANOVA was used to assess the effects of L-methionine on brain SAMe levels. Tukey (HSD) test was used for within and between group comparisons. Results were expressed as mean \pm S.E.M, and $\mathrm{p}<0.05$ considered significant.

\section{Results}

\subsection{Effect of L-methionine on Body Weight}

Table 2 represents the percentage weight change. $\mathrm{L}$-methionine at $10 \mathrm{mg} / \mathrm{kg}$ was associated with significant (F $(2,33)=9.41 \mathrm{p}<0.001)$ weight increase compared to distilled water. At $5 \mathrm{mg} / \mathrm{kg}$ the difference was not significant. There was no difference in food consumption amongst the groups.

Table 2. Effect of L-Methionine on \% weight change.

\begin{tabular}{cccc}
\hline Groups & Mean \pm S.E.M & P value & Tukey HSD \\
DW & $50.01 \pm 3.06$ & & \\
MET 5 & $55.59 \pm 2.26$ & $\mathrm{p}<0.16$ & 2.1932 \\
MET 10 & $65.41 \pm 2.21^{*}$ & $\mathrm{p}<0.01$ & 6.0575 \\
\hline
\end{tabular}

Comparison $^{*} \mathrm{p}<0.05$ vs. DW, number of mice per treatment group $=12$, DW: Distilled water, MET: Methionine

\subsection{Effects of L-methionine on horizontal locomotion}

Figure 1 shows the effect of L-methionine on locomotion in the open field. Two-factor ANOVA assessing the effects of two main factors (L-methionine dose and duration of administration) on horizontal locomotion revealed a significant effect of L-methionine dose $(\mathrm{F}(2,66)=26.6, \mathrm{p}<$ $0.001)$ and duration of administration $(\mathrm{F}(1,66)=33.9$, $\mathrm{p}<0.001)$ with significant interactions between L-methionine dose $x$ duration of administration $(\mathrm{F}(2,66)=11.4, \mathrm{p}<0.001)$. Pairwise comparisons of the effect of L-methionine dose (5 and $10 \mathrm{mg} / \mathrm{kg}$ ) with distilled water (control) following acute administration revealed a significant increase in horizontal locomotion with L-methionine at $10 \mathrm{mg} / \mathrm{kg}(\mathrm{p}<0.001)$. Repeated administration however resulted in significant decrease in locomotor activity at both $5(\mathrm{p}<0.0001)$ and 10 $\mathrm{mg} / \mathrm{kg}(\mathrm{p}<0.001)$ of L-methionine. Comparing the effects of acute and repeated dosing revealed a significant decrease in locomotor activity when repeated administration at $5 \mathrm{mg} / \mathrm{kg}$ $(\mathrm{p}<0.001)$ and $10 \mathrm{mg} / \mathrm{kg}(\mathrm{p}<0.001)$ is compared to acute administration. 


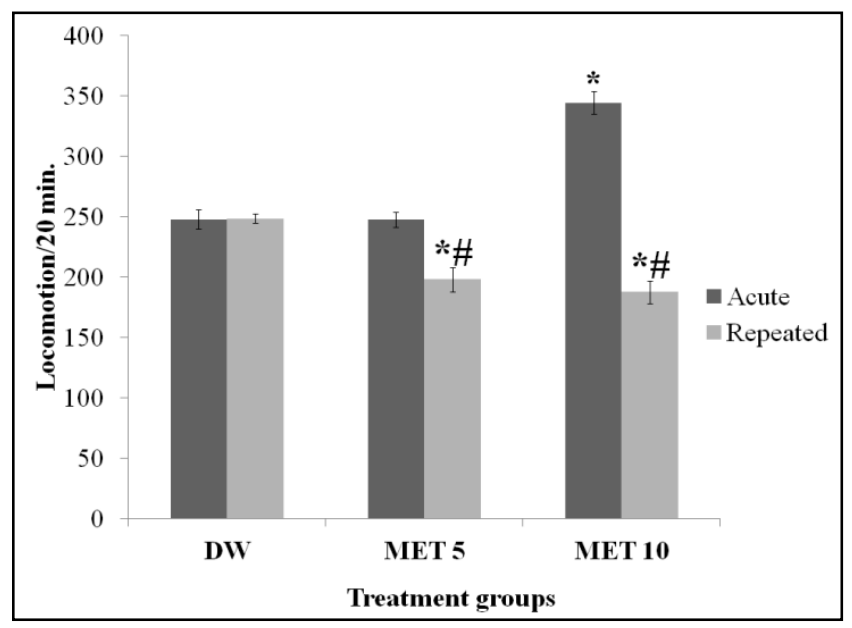

Figure 1. Effects of L-methionine on horizontal locomotion. Each bar represents mean \pm S.E.M, ${ }^{*} \mathrm{p}<0.05$ vs. DW, ${ }^{*} \mathrm{p}<0.05$ acute vs. repeated administraton, number of mice per treatment group $=12$, DW: Distilled water, MET: Methionine.



Figure 2 shows the effect of L-methionine on rearing in the open field. Two-factor ANOVA assessing the effects of two main factors (L-methionine dose and duration of administration) on rearing activity revealed significant effect of L-methionine dose $(\mathrm{F}(2,66)=7.44, \mathrm{p}<0.001)$ and duration of administration $(\mathrm{F}(1,66)=42.6, \mathrm{p}<0.001)$, with significant interaction between L-methionine dose $\mathrm{x}$ duration of administration $(\mathrm{F}(2,66)=9.32, \mathrm{p}<0.002)$. Pairwise comparisons of the effect of L-methionine dose with distilled water (control) following acute administration revealed a significant increase in rearing activity at $5(\mathrm{p}<0.001)$ and 10 $\mathrm{mg} / \mathrm{kg}(\mathrm{p}<0.001)$ of L-methionine. Repeated administration resulted in no significant difference at any of the doses. Comparisons of effect of acute and repeated dosing revealed significant decrease in rearing when repeated administration at $5(\mathrm{p}<0.0001)$ and $10 \mathrm{mg} / \mathrm{kg}(\mathrm{p}<0.011)$ is compared to acute administration.

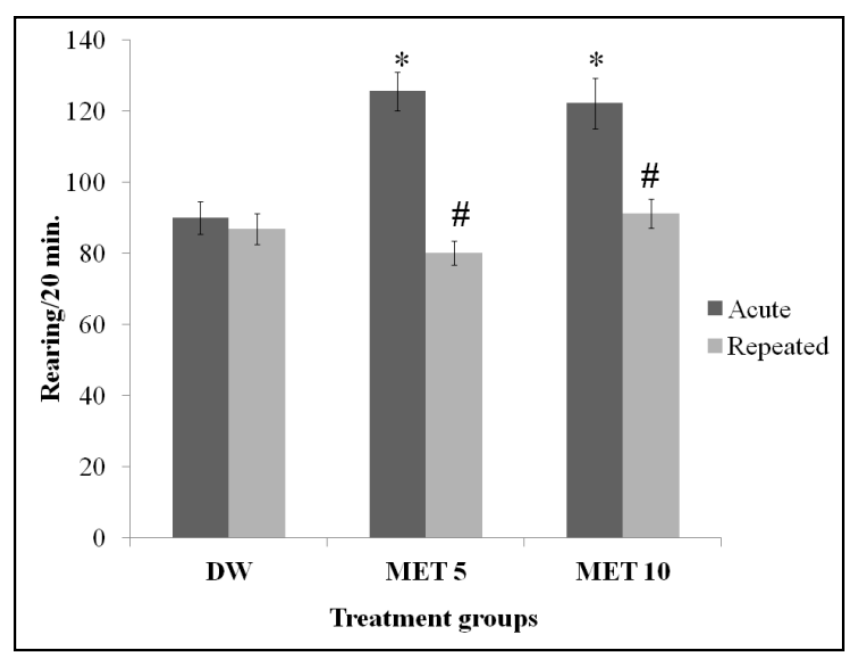

Figure 2. Effects of L-methionine on rearing activity. Each bar represents mean \pm S.E.M, ${ }^{*} \mathrm{p}<0.05$ vs. DW, ${ }^{*} \mathrm{p}<0.05$ acute vs. repeated administration, number of mice per treatment group $=12$, DW: Distilled water, MET: Methionine.

\subsection{Effects of L-methionine on Grooming}

Figure 3 shows the effect of L-methionine on grooming in the open field. Two-factor ANOVA assessing the effects of two main factors (L-methionine dose and duration of administration) on grooming behaviour revealed a significant effect of L- methionine dose $(\mathrm{F}(2,66)=21.4, \mathrm{p}<$ 0.001 ), no significant effect of duration of administration $(\mathrm{F}(1,66)=1.57, \mathrm{p}<0.214)$ and no interactions between L-methionine dose $\mathrm{x}$ duration of administration $(\mathrm{F}(2,66)=$ $0.201, \mathrm{p}<0.818$ ). Pairwise comparisons of the effect of L-methionine dose and distilled water (control) revealed a significant decrease in grooming at $5(\mathrm{p}<0.008 ; \mathrm{p}<0.001)$ and $10 \mathrm{mg} / \mathrm{kg}(\mathrm{p}<0.008 ; \mathrm{p}<0.0011)$, following acute and repeated administration respectively. Comparisons of the effects of acute and repeated dosing revealed no significant difference at any of the doses when repeated administration is compared to acute administration.

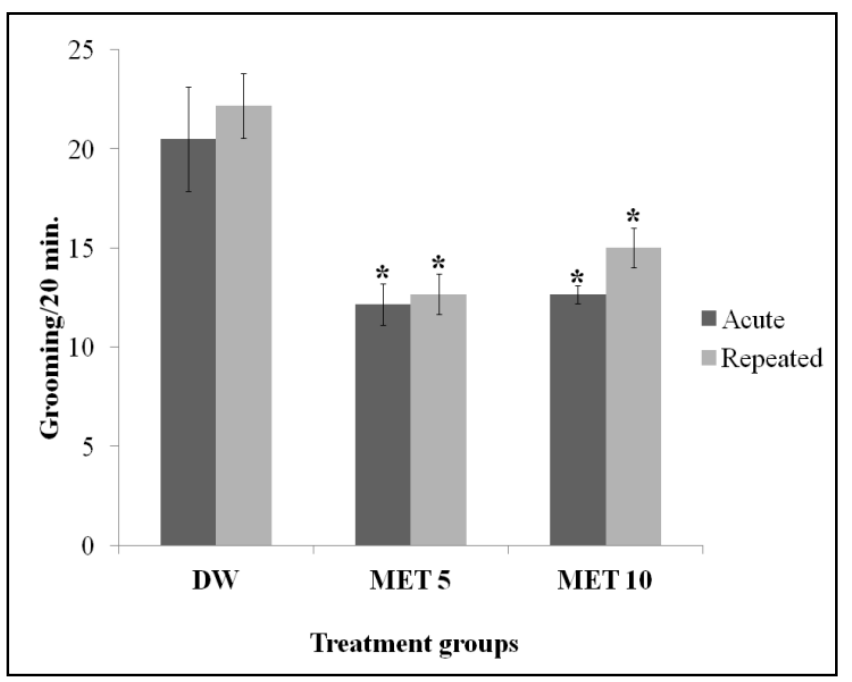

Figure 3. Effects of L-methionine on grooming behaviour. Each bar represents mean \pm S.E.M, ${ }^{*}$ p $<0.05$ vs. DW, ${ }^{*}$ < $<0.05$ acute vs. repeated administration, number of mice per treatment group $=12$, DW: Distilled water, MET: Methionine.

\subsection{Effect of L-methionine on Y-maze Spatial Working Memory Tasks}

Figure 4 shows the effect of L-methionine on \% alternation in the Y-maze. Two-factor ANOVA assessing the effect of two main factors (L-methionine dose and duration of administration) on spatial working memory revealed significant effect of L-methionine dose $(F(3,88)=32.1$, $p<$ 0.001 ), no significant effect of duration of administration $(F(1,88)=0.156, p<0.693)$ and no interactions between L-methionine dose $x$ duration of administration $(F(3,88)=$ $0.902, \mathrm{p}<0.443)$. Pairwise comparisons of the effect of scopolamine (SCOP) or L-methionine dose and distilled water (control) revealed a significant decrease in working memory (measured as \% alternation) with SCOP ( $<<0.001$; $\mathrm{p}<0.001$ ) following acute and repeated administration, but no significant difference seen at any of the doses of 
L-methionine with either acute or repeated administration. Compared to SCOP, there was a significant increase in working memory at $5(\mathrm{p}<0.001 ; \mathrm{p}<0.001)$ and $10 \mathrm{mg} / \mathrm{kg}$ ( $\mathrm{p}<$ $0.001 ; \mathrm{p}<0.001)$ of L-methionine following acute and repeated administration respectively. Comparisons of the effect of acute and repeated dosing revealed no significant difference in memory at any of the doses when repeated administration is compared to acute administration.

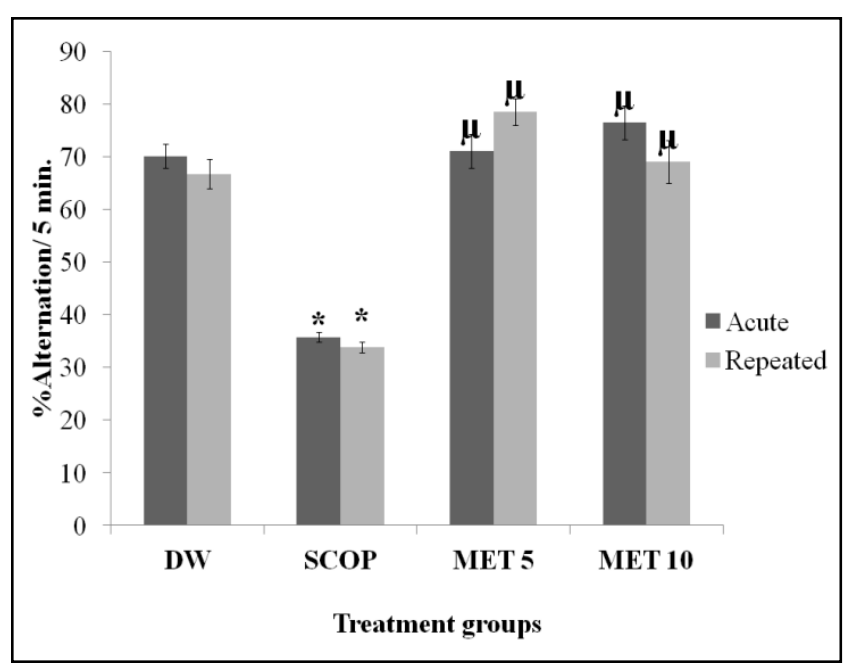

Figure 4. Effects of L-methionine on Y-maze memory tasks. Each bar represents mean \pm S.E.M, ${ }^{*} \mathrm{p}<0.05$ vs. DW, ${ }^{\mu} \mathrm{p}<0.05$ vs. SCOP, ${ }^{*} \mathrm{p}<0.05$ acute vs. repeated administration, number of mice per treatment group $=12$; DW: Distilled water, SCOP: Scopolamine, MET: Methionine.

\subsection{Effect of L-methionine on Radial-arm Maze Spatial Working Memory Tasks}

Figure 5 shows the effects of L-methionine on radial-arm maze spatial-working memory, measured as alternation index $/ 5$ minute, which is a fraction of number of correct alternation before first error and total number of alternations made in a five minute period. Two-factor ANOVA assessing the effect of two main factors (L-methionine dose and duration of administration) on spatial working memory in the radial-arm maze revealed a significant effect of L-methionine dose $(F(3,88)=29.7, p<0.001)$, no significant effect of duration of administration $(F(1,88)=0.03, p<0.863)$ and no interactions between $\mathrm{L}$-methionine dose $\mathrm{x}$ duration of administration $(\mathrm{F}(3,88)=2.24, \quad \mathrm{p}<0.089)$. Pairwise comparisons of the effect of SCOP or L-methionine dose and distilled water (control) following acute administration revealed a significant decrease in memory with SCOP ( $p<$ 0.002 ) and no significant difference at any of the doses of L-methionine. With repeated administration, a significant decrease in memory was seen with SCOP $(p<0.001)$, at 5 $(p<0.043)$ and $10 \mathrm{mg} / \mathrm{kg}(\mathrm{p}<0.032)$ of L-methionine. Compared to SCOP, there was significant increase in memory at $5(\mathrm{p}<0.001 ; \mathrm{p}<0.001)$ and $10 \mathrm{mg} / \mathrm{kg}(\mathrm{p}<0.001$; $\mathrm{p}<0.001)$ of L-methionine following acute and repeated administration respectively. Comparisons of the effect of acute versus repeated dosing revealed a significant decrease in alternation index with repeated administration at $5 \mathrm{mg} / \mathrm{kg}$ $(p<0.030)$, compared to acute administration.

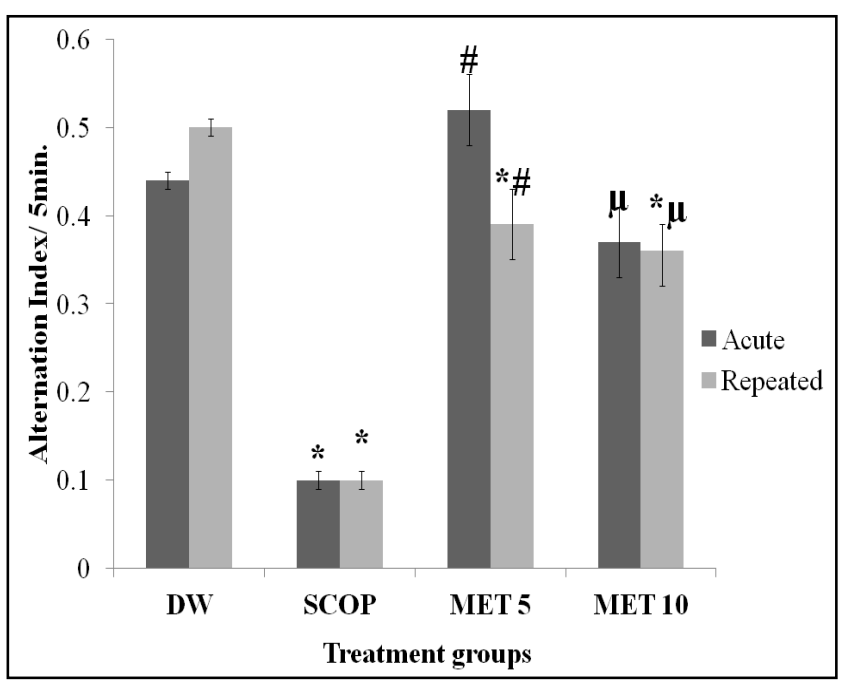

Figure 5. Effects of L-methionine on radial arm maze memory tasks. Each bar represents mean \pm S.E.M, ${ }^{*} \mathrm{p}<0.05$ vs. DW, ${ }^{\mu} \mathrm{p}<0.05$ vs. SCOP, ${ }^{\#} \mathrm{p}<0.05$ acute vs. repeated administration, number of mice per treatment group =12; DW: Distilled water, SCOP: Scopolamine, MET: Methionine.

\subsection{Effect of L-methionine on Anxiety Behaviour}

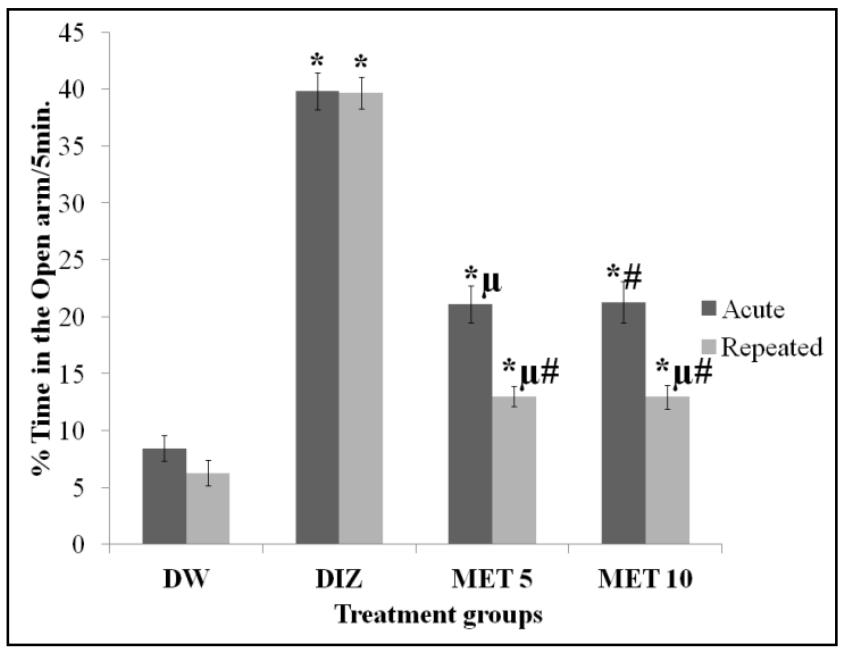

Figure 6. Effects of L-methionine on \% time spent in the open arm of the elevated plus maze. Each bar represents mean \pm S.E.M, ${ }^{*} \mathrm{p}<0.05$ vs. DW, ${ }^{\mu} \mathrm{p}<0.05$ vs. DIZ, ${ }^{\#} \mathrm{p}<0.05$ acute vs. repeated administration, number of mice per treatment group $=12$; DW: Distilled water, DIZ: diazepam, MET: Methionine.

Figure 6 shows the effect of L-methionine on $\%$ time spent in the open arm of the EPM. Two-factor ANOVA revealed a significant effect of L-methionine dose $(\mathrm{F}(3,88)=169$, $\mathrm{p}<0.001)$ and duration of administration $(\mathrm{F}(\mathrm{F}(1,88)=19.8$, $\mathrm{p}<0.002)$, with significant interactions between L-methionine dose $\mathrm{x}$ duration of administration $(\mathrm{F}(3,88)=$ $3.85, \mathrm{p}<0.012)$. Pairwise comparisons of the effect of diazepam (DIZ) or L-methionine dose and distilled water (control) following acute administration revealed a 
significant increase in time spent in the open arms with DIZ $(p<0.001 ; p<0.001)$, at $5(p<0.001 ; p<0.001)$ and $10 \mathrm{mg} / \mathrm{kg}$ $(\mathrm{p}<0.001 ; \mathrm{p}<0.010)$ of L-methionine following acute and repeated administration respectively. Compared to DIZ, there was a significant decrease in time spent in the open arms at $5(\mathrm{p}<0.001 ; \mathrm{p}<0.001)$ and $10 \mathrm{mg} / \mathrm{kg}(\mathrm{p}<0.001 ; \mathrm{p}<$ 0.001 ) of L-methionine following acute and repeated administration respectively. Comparisons of the effect of acute and repeated dosing revealed significant increase in time spent in the open arms when repeated administration at $5(\mathrm{p}<0.003)$, and $10 \mathrm{mg} / \mathrm{kg}(\mathrm{p}<0.006)$ of L-methionine is compared to acute administration.

\subsection{Effects of L-methionine on Locomotor Activity in the Y-maze, Radial-arm Maze and Elevated Plus-maze}

Table 3 shows the effect of L-methionine on locomotor activity measured as total arm entry in the $\mathrm{Y}$ and radial-arm maze and \% time spent in the closed arm in the EPM respectively.

Following exploration in the Y-maze, two-factor ANOVA revealed a significant effect of L-methionine dose $(\mathrm{F}(3,88)=$ $25.8, \mathrm{p}<0.001)$ and duration of administration $(\mathrm{F}(1,88)=$ 27.4, $\mathrm{p}<0.001)$ with significant interaction between L-methionine dose $x$ duration of administration $(F(3,88)=$ $9.45, \mathrm{p}<0.002)$. Pairwise comparisons of the effect of SCOP or L-methionine dose and distilled water (control) following acute administration revealed a significant increase in locomotor activity with SCOP $(\mathrm{p}<0.001)$ and at $5 \mathrm{mg} / \mathrm{kg}(\mathrm{p}<$ 0.004) of L-methionine. With repeated administration, a significant increase is seen with SCOP $(\mathrm{p}<0.001)$ and a significant decrease at $5(\mathrm{p}<0.001)$ and $10 \mathrm{mg} / \mathrm{kg}(\mathrm{p}<0.001)$ of L-methionine. Compared to SCOP, there was a significant decrease in locomotor activity at $5(\mathrm{p}<0.022, \mathrm{p}<0.010)$ and $10 \mathrm{mg} / \mathrm{kg}(\mathrm{p}<0.002, \mathrm{p}<0.031)]$ of L-methionine following acute and repeated administration respectively. Comparison of the effect of acute and repeated dosing revealed significant a decrease in locomotor activity with repeated administration at $5(\mathrm{p}<0.004)$ and $10 \mathrm{mg} / \mathrm{kg}(\mathrm{p}<0.009)$ compared to acute administration.

Following exploration in the radial-arm maze, two-factor ANOVA revealed a significant effect of L-methionine dose $(\mathrm{F}(3,88)=221, \mathrm{p}<0.001)$ and duration of administration $(\mathrm{F}$ $(1,88)=14.8, \quad \mathrm{p}<0.002)$, with significant interactions between L-methionine dose $\mathrm{x}$ duration of administration $(\mathrm{F}(3,88)=3.45, \mathrm{p}<0.020)$. Pairwise comparisons of the effect of SCOP or L-methionine dose and distilled water (control) revealed a significant increase in locomotor activity with SCOP $(p<0.001, p<0.001)$ but no significant difference at either dose of L-methionine following acute and repeated administration respectively. In comparison to SCOP, there was a significant decrease in locomotor activity at $5(\mathrm{p}<0.001 ; \mathrm{p}<0.001)$ and $10 \mathrm{mg} / \mathrm{kg}(\mathrm{p}<0.001 ; \mathrm{p}<0.001)$ of L-methionine following acute and repeated administration respectively. Comparisons of the effect of acute and repeated dosing revealed significant decrease in locomotor activity when repeated administration at $5(\mathrm{p}<0.001)$ and $10 \mathrm{mg} / \mathrm{kg}$ $(\mathrm{p}<0.046)$ is compared to acute administration.

Effect of L-methionine on locomotor activity was measured as \% time spent in the closed arm of the EPM. Two-factor ANOVA revealed a significant effect of L-methionine dose $(\mathrm{F}(3,88)=20.7, \mathrm{p}<0.001)$ and duration of administration $(\mathrm{F}(1,88)=23.6, \mathrm{p}<0.001)$, with significant interaction between L-methionine dose $\mathrm{x}$ duration of administration $(\mathrm{F}(3,88)=8.85, \mathrm{p}<0.001)$. Comparisons of the effect of DIZ or L-methionine dose and distilled water (control) following acute administration revealed a significant decrease in time spent in the closed arm with DIZ $(p<0.004)$, but a significant increase at $5(p<0.033)$ and 10 $\mathrm{mg} / \mathrm{kg}(\mathrm{p}<0.032)$ of methionine. Repeated administration revealed in a significant decrease in time spent in the closed arm with DIZ $(p<0.001)$ but no significant difference at any of the doses of L-methionine.

In comparison to DIZ, there was a significant increase in time spent in the closed arm at $5(\mathrm{p}<0.013 ; \mathrm{p}<0.001), 10$ $\mathrm{mg} / \mathrm{kg}(\mathrm{p}<0.001 ; \mathrm{p}<0.001)$ of L-methionine following acute and repeated administration respectively. Comparisons of the effect of acute and repeated dosing revealed significant decrease in time spent in the closed arm when repeated administration at $5(\mathrm{p}<0.001)$ and $10 \mathrm{mg} / \mathrm{kg}(\mathrm{p}<0.001)$ is compared to acute administration.

Table 3. Showing effect of L-methionine on locomotor activity in the Y-maze, radial-arm maze and EPM

\begin{tabular}{|c|c|c|c|}
\hline $\begin{array}{c}\text { Locomotor } \\
\text { activity }\end{array}$ & Groups & $\begin{array}{c}\text { Acute } \\
\text { Mean } \pm \text { S.E.M }\end{array}$ & $\begin{array}{c}\text { Repeated } \\
\text { Mean } \pm \text { S.E.M }\end{array}$ \\
\hline \multirow[t]{4}{*}{ Y-maze } & DW & $7.00 \pm 0.52$ & $6.58 \pm 0.47$ \\
\hline & SCOP & $13.5 \pm 0.29 *$ & $13.83 \pm 0.61 *$ \\
\hline & MET 5 & $11.25 \pm 0.86^{* \mu}$ & $3.33 \pm 1.48^{* \mu \#}$ \\
\hline & MET 10 & $9.50 \pm 1.11^{\mu}$ & $2.50 \pm 1.76^{* \mu \#}$ \\
\hline \multirow[t]{4}{*}{ Radial-arm } & DW & $11.00 \pm 1.14$ & $11.75 \pm 1.05$ \\
\hline & SCOP & $43.00 \pm 1.85^{*}$ & $44.92 \pm 2.63^{*}$ \\
\hline & MET 5 & $9.00 \pm 0.92^{\mu}$ & $18.50 \pm 0.75^{* \mu}$ \\
\hline & MET 10 & $11.75 \pm 0.72^{\mu}$ & $15.67 \pm 1.67^{\mu \#}$ \\
\hline \multirow[t]{4}{*}{ EPM } & DW & $71.36 \pm 4.87$ & $76.358 \pm 5.04$ \\
\hline & DIZ & $55.47 \pm 0.53 *$ & $52.67 \pm 4.17^{*}$ \\
\hline & MET 5 & $59.75 \pm 1.50^{* \mu}$ & $86.07 \pm 2.31^{\mu \#}$ \\
\hline & MET 10 & $66.14 \pm 2.84^{* \mu}$ & $84.41 \pm 1.89^{\mu \#}$ \\
\hline
\end{tabular}

Comparisons: ${ }^{*} \mathrm{p}<0.05$ vs. DW, ${ }^{\mu} \mathrm{p}<0.05$ vs. SCOP or DIZ, ${ }^{*} \mathrm{p}<0.05$ acute vs. repeated administration, number of mice per treatment group $=12$; DW: Distilled water, SCOP: scopolamine, DIZ: Diazepam, MET: Methionine, EPM: Elevated plus maze.

\subsection{Effects of L-methionine on Brain Levels of $S$ adenosyl Methionine (SAMe)}

Table 4 shows the effect of repeated oral administration of L-methionine on SAMe levels in the rat brain. There was no significant $(\mathrm{p}<0.451)$ difference in brain levels of SAMe at either doses of L-methionine compared to distilled water (control). 
Table 4. Showing effect of repeated oral administration of L-methionine on brain SAMe levels

\begin{tabular}{cccc}
\hline Groups & Mean \pm S.E.M & P value & Tukey HSD \\
DW & $14.90 \pm 1.06$ & & \\
MET 5 & $15.70 \pm 1.16$ & $\mathrm{p}<0.27$ & $\mathrm{Q}=1.1222$ \\
MET 10 & $16.20 \pm 1.21$ & $\mathrm{p}<0.32$ & $\mathrm{Q}=0.8436$ \\
\hline
\end{tabular}

Comparison ${ }^{*} \mathrm{p}<0.05$ vs. DW, number of mice per treatment group $=12$, DW: Distilled water, SAMe: S-adenosyl methionine, MET: Methionine

\section{Discussions}

Our study of the effects of low dose methionine administration in young rats revealed that methionine was associated with: (1) weight gain (2) a mixed response to novelty in the open field (3) memory impairment in the radial-arm maze (4) anxiolytic effect (5) a non-significant increase in brain levels of SAMe.

Administration of L-methionine caused a significant increase in weight, in the present study. A number of studies have reported that L-methionine did not cause any weight gain, while in others, diets deficient in methionine has been reported to cause weight loss. Hegedüs et al., [27] reported weight gain in rats fed methionine-supplemented diet at 1.5 and $3.0 \mathrm{~g} / \mathrm{kg}$; this corroborates the results of our study, however, the studies differ in two aspects: (1) mode of methionine administration and, (2) dose administered. On the contrary, methionine-restricted diet has been reported to cause reduction in weight gain by increasing energy expenditure and reducing visceral fat stores [28]. In the present study, weight gain at $10 \mathrm{mg} / \mathrm{kg}$ may be attributed to increase in food consumption/visceral fat stores or a decrease in energy expenditure. It is noteworthy that food or water intake did not increase significantly at any of the doses of L-methionine when compared to distilled water controls (Data not shown).

Administration of L-methionine was excitatory with acute administration and inhibitory with repeated administration as shown by changes in horizontal locomotion and rearing respectively. Alterations in locomotor activity have been associated with changes in activity of dopamine (DA) in the brain in a number of studies [29]. Locomotor retardation that was seen with repeated administration could be due to SAMe-induced methylation at the DA synaptic cleft, receptor-bound DA, or DA receptors [30]. Studies have shown that SAMe inhibits ligand-binding to dopamine (DA) receptors [31], resulting in a down-regulation of DA receptors. Stimulation of inhibitory gamma amino-butyric acid (GABA) receptors could also be responsible for this effect. Locomotor retardant effects of methionine at doses $>100 \mathrm{mg} / \mathrm{kg}$ have been reported previously [17].

Grooming is a very important behaviour that is observable in a number of animals. In this study, a decrease in grooming frequency is seen with both acute and repeated administration of methionine. Grooming is regulated by multiple regions in the brain under the influence of several neuromediators and hormones [32]. A decrease in grooming could be due to inhibition of dopamine receptors (D1), also as a result of SAMe methylation causing a down regulation $[30,31]$, or the activation of GABA $A$ and GABA $B$ receptors [33], which reduces grooming frequency.

Spatial memory is modulated through influences of cholinergic, glutamatergic or GABAergic projections to a number of brain regions [34,35]. In this study, acute or repeated administration of L-methionine in the Y-maze resulted in an increase in memory that was only visual. In the radial-arm maze, acute administration at $5 \mathrm{mg} / \mathrm{kg}$ showed a visual increase, while repeated administration resulted in a decrease in memory scores. The presence of a mixed response could point to the presence of early and late neurotransmitter responses, or receptor saturation with increasing administration. Studies have reported memory impairment [11,14-17] with methionine at higher doses, regardless of mode of administration; and these has been attributed to increases in brain oxidative stress [11]. An activation of GABAergic inputs in the median septum also impairs spontaneous alternation working-memory [35]. An initial, non-significant improvement in memory may be attributable to marginal increases in brain SAMe levels which have been reported to cause an increase in choline levels and hence improve memory [20], however, subsequent activation of other mechanisms such as activation of GABAergic inputs in the median septum could impair spontaneous alternation working-memory.

Behaviour in the EPM is based on the natural aversion of rodents for elevated and open spaces. The results of the EPM test in this study revealed that acute and repeated administration of L-methionine resulted in a dose-related anxiolytic response. Despite the fact that there is a dearth of information on the effect of oral L-methionine on anxiety-related behaviours, the antidepressant effects of SAMe and L-methionine at low doses $(25 \mathrm{mg} / \mathrm{kg})$ have been reported [7]. Anxiety-related disorders are usually a consequence of complex, multi-feedback mechanisms involving serotonin, dopamine, and norepinephrine neurotransmitter systems; all of which have been implicated in anxiety-related disorders [36,37]. The effects of L-methionine on any of these neurotransmitters could be responsible for the anxiolytic effect seen with repeated administration.

Administration of low doses of L-methionine in this study increased brain levels of SAMe, albeit only visually. This results corroborate studies that have shown that oral administration of methionine altered brain SAMe levels [7]. The present study however differs from that of Young and Shalachi, in that regional brain levels were assayed compared to whole brain SAMe in our study. However, the results of behavioural tests in this study support the fact that brain SAMe levels differ from one region to another; results seen with memory tests could be due to lower SAMe levels in the hippocampus, while effects on locomotion, rearing and grooming could point to higher levels in the cerebral cortex, cerebellum or spinal cord. The differences in SAMe 
levels in different brain regions with methionine administration has been suggested to reflect regional differences in methionine metabolism, possibly due to differences in methionine adenosyltransferase activity.

\section{Conclusions}

This study concludes that low doses of L-methionine can alter brain function in young rats. A tendency towards memory impairment is still present; therefore caution in its use in the young is suggested.

\subsection{Conflict of Interest}

All authors of this paper declare that there is no conflict of interest related to the content of this manuscript.

\subsection{Source of Funding}

This research did not receive any specific grant from agencies in the public, commercial, or not-for-profit sectors.

\section{REFERENCES}

[1] C Tapia-Rojas, CB Lindsay, C Montecinos-Oliva, MS Arrazola, RM Retamales, D Bunout, S Hirsch, Inestrosa NC. Is L-methionine a trigger factor for Alzheimer's-like neurodegeneration? Changes in $\mathrm{A} \beta$ oligomers, tau phosphorylation, synaptic proteins, Wnt signaling and behavioral impairment in wild-type mice Mol. Neurodegen 10(62) 2015. doi: 10.1186/s13024-015-0057-0.

[2] JD Finkelstein, JJ Martin, BJ Harris. Methionine metabolism in mammals. The methionine-sparing effect of cystine. J. Biol. Chem. 263:11750-54, 1988.

[3] PK Dash, GW Hergenroeder, CB Jeter, HA Choi, N Kobori, AN Moore. Traumatic brain injury alters methionine metabolism: implications for Pathophysiology. Front. Syst. Neurosci. 10:36, 2016.http://dx.doi.org/10.3389/fnsys.2016 .00036

[4] AL Miller. Alt. Med. Rev. 8(1):7-19, 2003.

[5] ER Stadtman, J Moskovitz, RL Levine. Oxidation of methionine residues of proteins: biological consequences. Antioxid Redox Signal 5(5):577-82, 2003.

[6] ML Orgeron, KP Stone, D Wanders, CC Cortez, NT Van, TW Gettys. The impact of dietary methionine restriction on biomarkers of metabolic health. Prog Mol Biol Transl Sci. 121: 351-376, 2014. doi: 10.1016/B978-0-12-800101-1.00 011-9.

[7] SN Young, M Shalchi. The effect of methionine and $S$-adenosylmethionine on $S$-adenosyl methionine levels in the rat brain J Psychiatry Neurosci. 30(1):44-48, 2005.

[8] LK Revelle, DA Davignon, J Reepmeyer, RC Zerfing. Stability indicating proton nuclear magnetic resonance spectroscopic method for determination of $S$-adenosyl-L-methionine in tablets. J AOAC Int 78:353-8, 1995.

[9] RA Rubin, LA Ordonez, RJ Wurtman. Physiological dependence of brain methionine and $S$-adenosylmethionine concentrations on serum amino acid pattern. $J$ Neurochem 23:227-31, 1874 .

[10] WM Pardridge. Blood-brain barrier transport of nutrients. Nutr Rev 44 Suppl: 15-25, 1986.

[11] KH Alzoubi, OF Khabour, SI Al-Azzam, MH Tashtoush, NM Mhaidat. Metformin eased cognitive impairment induced by chronic 1-methionine administration: Potential role of oxidative stress. Curr Neuropharmacol. 12(2):186-92, 2014.

[12] L Tremolizzo, G Carboni, WB Ruzicka, CP Mitchell, I Sugaya, P Tueting, R Sharma, DR Grayson, E Costa, A Guidotti. An epigenetic mouse model for molecular and behavioral neuropathologies related to schizophrenia vulnerability. Proc Natl Acad Sci USA 99:17095-100, 2002.

[13] L Wang, A Alachkar, N Sanathara, JD Belluzzi, Z Wang, O Civelli. A methionine-induced animal model of schizophrenia: Face and predictive validity. Int $J$ Neuropsychopharmacol. 18(12), 2015. doi: 10.1093/ijnp/py v054

[14] FC Vuaden, LE Savio, AL Piato, TC Pereira, MR Vianna, MR Bogo, CD Bonan, AT Wyse. Long-term methionine exposure induces memory impairment on inhibitory avoidance task and alters acetylcholinesterase activity and expression in zebrafish (Daniorerio). Neurochem Res 37(7):1545-53, 2012. doi: 10.1007/s11064-012-0749-6.

[15] MM de Rezende, V D'Almeida. Central and systemic responses to methionine-induced hyperhomocysteinemia in mice PLoS ONE 9(8), 2014. doi:10.1371/journal.pone.0105 704

[16] RR Parrish, S Buckingham, KL Mascia, JJ Johnson, MM Matyjasik, RM Lockhart, FD Lubin. Methionine increases BDNF DNA methylation and improves memory in epilepsy Ann Clin Transl. Neurol. 2(4):401-416, 2015.

[17] A Viggiano, E Viggiano, M Monda, D Ingrosso, SF Perna, B De Luca. Methionine-enriched diet decreases hippocampal antioxidant defences and impairs spontaneous behaviour and long-term potentiation in rats Brain Res. 1471:66-74, 2012.

[18] LA Christie, G Riedel, B Platt. Bi-directional alterations of LTP after acute homocysteine exposure. Behav. Brain Res. 205, 559-563, 2009.

[19] SA Algaidi, LA Christie, AM Jenkinson, L Whalley, G Riedel, B Platt. Long-term homocysteine exposure induces alterations in spatial learning, hippocampal signalling and synaptic plasticity. Exp. Neurol. 197, 8-21, 2006.

[20] A Chan, F Tchantchou, V Graves, R Rozen, TB Shea. Dietary and genetic compromise in folate availability reduces acetylcholine and cognitive performance: critical role of S-adenosylmethionine. J Nutr Health Aging 12:252-261, 2008.

[21] CLD Amaral, RBL Bueno, RV Burim, RH Queiroz, MLP 
Bianchi, LMG Antunes. The effects of dietary supplementation of methionine on genomic stability and $p 53$ gene promoter methylation in rats.Mutat. Res./Genet. Toxicol. Environ. Mutagen. 722:78-83, 2011.

[22] PJ Garlick. Toxicity of methionine in humans. J Nutr. $136(6$ Suppl):1722S-5, 2006.

[23] National Research Council. Recommended dietary allowances. $10^{\text {th }}$ ed. Washington: National Academy Press; 1989.

[24] OJ Onaolapo, AY Onaolapo, MA Akanmu, G Olayiwola. Foraging enrichment modulates open field response to monosodium glutamate in mice, Annal. Neurosci. 22(3): 162-170, 2015.

[25] OJ Onaolapo, AY Onaolapo, OR Akinola, TO Anisulowo. Dexamethasone regimens alter spatial memory and anxiety levels in mice; J.Behav. Brain Sc., 4, 159-167, 2014.

[26] OJ Onaolapo, AY Onaolapo, EO Awe, N Jibunor, B Oyeleke, AJ Ogedengbe. Oral artesunate-amodiaquine combination causes anxiolysis and impaired cognition in healthy Swiss mice. IOSR: JPBS 7(2): 97-102, 2013.

[27] M Hegedüs, S Fekete, E Andrásofszky, I Hullár._Effect of methionine and its derivatives on the weight gain and protein utilisation of growing rats._Acta Vet Hung 46(4):421-9, 1998.

[28] AF Aissa, TDUH Gomes, MR Almeida, LC Hernandes, JDC Darin, MLP Bianchi, LMG Antunes. Methionine concentration in the diet has a tissue-specific effect on chromosomal stability in female mice Food and Chem. Tox. 62:56-462, 2013.

[29] RJ Beninger. The role of dopamine in locomotor activity and learning. Brain Res. 287(2):173-96, 1983.

[30] CG Charlton. Methylation reactions at dopaminergic nerve endings, serving as biological off-switches in managing dopaminergic functions. Neural Regen Res 9:1110-1, 2014.

[31] ES Lee, H Chen, KR Shepherd, NS Lamango, KF Soliman, CG Charlton. The inhibitory role of methylation on the binding characteristics of dopamine receptors and transporter. Neurosci Res 48:335-344, 2004.

[32] KC Berridge, JW Aldridge. Super-stereotypy I: enhancement of a complex movement sequence by systemic dopamine D1 agonists. Synapse. 37,194-204, 2000.

[33] HM Barros, SL Tannhauser, MA Tannhauser, M Tannhauser. The Effects of GABAergic drugs on grooming behaviour in the Open field, Pharmacol. Toxicol. 74(4-5):339-44, 1994.

[34] F Khakpai, M Nasehi, A Haeri-Rohani, A Eidi, MR Zarrindast. Scopolamine induced memory impairment; Possible involvement of NMDA receptor mechanisms of dorsal hippocampus and/or septum. Behav. Brain Res. 231(1):1-10, 2012.

[35] A Degroot, MB Parent. Increasing acetylcholine levels in the hippocampus or entorhinal cortex reverses the impairing effects of septal GABA receptor activation on spontaneous alternation. Learn. Mem. 7:293-302, 2000.

[36] AW Goddard, SG Ball, J Martinez. Current perspectives of the roles of the central norepinephrine system in anxiety and depression. Depress Anxiety. 27(4):339-350, 2010.

[37] DS Charney. Neuroanatomical circuits modulating fear and anxiety behaviors. Acta Psych. Scand. S (417):38-50, 2003. 